\title{
Semiotic Analysis of the Symbolic World of the Culture Complex
}

Zharkynbek Abikenov ${ }^{+*}$, Tursun Gabitov, ${ }^{\dagger}$ Ongar Bermakhanov, ${ }^{\text {vl }}$ Aigul Abdiramanova,' and Murat Nassimov ${ }^{\text {l }}$

\section{Abstract}

This research probes the symbolic meaning of the Korkyt Ata Complex aimed at understanding the cultural and spiritual life of the ancient Turkic people. Perhaps, this is the first instance when the semiotic analysis technique has been applied to studying the Korkyt Ata Complex in a broader context of Kazakh culture. Thus, the research is an attempt to reveal its symbolic cultural significance to the Kazakh society using a semiotic methodology as the basis to study the cultural monuments. The role of the Korkyt Ata memorial in the formation of ancient Turkic civilisation was considered from a socio-cultural and philosophical perspective. The symbolic elements of the culturally bound worldview that were depicted in the Korkyt Ata memorial were analysed via the methodological bases of symbolic representations. The symbolic side of the memorial was defined in spiritual, cultural and worldview spheres. The Complex, its external sides specifically, underwent a semiotic analysis to accomplish the above-mentioned objectives.

Keywords: The Semiotics of Ancient Architecture, Symbolic Cultural Figures, The Symbolic Meaning of Monuments, Symbolic World of Ancient Turkic people, Ancient Turkic Culture, Cultural Monuments

\footnotetext{
${ }^{\dagger}$ Al-Farabi Kazakh National University, 71 Al-Farabi av., Almaty 050040 Kazakhstan

${ }^{*}$ Corresponding Author,Email: abikenovkz@gmail.com

${ }^{v}$ Korkyt Ata Kyzylorda State University, 29A Aiteke bi av., Kyzylorda, 120014 Kazakhstan

${ }^{1}$ University Bolashak, 31Abai av., Kyzylorda 120008 Kazakhstan

(C) 2019 Abikenov et al. This is an Open Access article distributed under the terms of the Creative Commons Attribution License (http://creativecommons.org/licenses/by/2.0), which permits unrestricted use, distribution, and reproduction in any medium, provided the original work is properly cited.
} 


\section{Introduction}

There are distinguished figures that have been able to define particular era in terms of its spirit and essence. It is impossible to overlook the contributions of those figures. Korkyt Ata is being one of them. Here, we try to understand the pre-Islamic Tengrian worldview, which was widespread among the Turkic peoples from the ancient times.

This research, however, shall not focus on Korkyt the Kazakh, Korkyt the Character or Korkyt the Historical Figure - these are three images of Korkyt currently present in the discourse rather we aim to reveal a symbolic cultural meaning of Korkyt Ata Complex.

The research is premised on the argument that architecture may help to establish new facts and may become a source of new knowledge provided the focus is shifted from architectural styles and techniques to the content and meaning that were supposedly conveyed by them. Therefore, this research aims to study the visual 'text' created within the cultural dimension of architecture, particularly the use of space as a visual message. Semiotic tools are employed here to demonstrate how the formal architectural expression formulates the meaning to prompt particular readings of a reference object.

Other forms of visual engagement are necessary to create an environment suitable for prayers. While we consider the notions of paradise, cosmos, and creation as the most probable sources of inspiration for the ancient Kazakh artists, the fact that the Kazakh liturgy does not provide any hint as to how the places of worship should be designed raising the question of how the architects might have selected the concepts that were suitable to be represented by the complex. This question is difficult to answer because of the lack of data on the design procedures of those times. Architects did not leave any records on the rituals associated with the construction works or any texts explaining their work. Therefore, this research attempts to tell about the purpose (in the broadest sense) of those architects in creating those buildings. The hypothesis discussed herein consists of the following: first, the architects of that period used the "language of architecture" to express specific ideas and second, given that Kazakh tradition prevailed during that era, mosques were built as symbolic texts depicting the paradise as it was preserved in the Kazakh tradition.

To that end, the author employs the semiotic tools to analyse the architectural language of the Korkyt Ata Complex and discusses how the architecture is to be "read" by those who encounter it. Thus, the research has the following goals:

- to show the architectural language of the building as a text;

- to trace the historical cultural trends of that period and place them within the context of the dominant style of architecture; and

- to see a building as a formal expression from a semiotic perspective.

The author justifies the use of semiotic analysis of the formal expression of the Kazakh architecture to identify the patterns of the construction of meaning. In doing so, the research provides a full reading of the architectural text of the Korkyt Ata Complex.

The paper consists of the following sections. The introduction and the main theory section provide theoretical insights into the subject. The methods section indicates semiotics as a tool for analysing architectural pieces of art. The following section is devoted to results and the analysis of the same. The conclusion summarises the results of the research.

\section{Methods}

In terms of its methods, the research discusses the results of a complex semiotics analysis of the symbols of the Korkyt Ata Complex. Much attention has been paid to "search for eternal life" when kobyz-specific nature of the Complex guides were used to analyse the subject. For interpretation in the context of cultural 
symbolism, the integrity of the national identity is central to deriving answers methodologically from the works of Y.M. Lotman, Peirce and E. Cassirer (2002). The authors used the methods as a means of generalisation, in order to describe and summarise the interpretation of the semiotic symbols. In a similar context, this research primarily focuses on the semiotic analysis of cultural values, pragmatic comprehension, on the analysis of Kazakh traditions, and the influence projected by the Complex on the human beings.

The discussion in the research is interdisciplinary by its nature. This is because it includes architectural theory and history, on the one hand, and semiotics and theories related to semiotics on the other hand. The following methods were used to deal with architecture as a text:

- a purposive study of the models of semiology and their applications in visual communication;

- a contextual study for a selected case that represents a rich cultural content;

- a diachronic analysis of the Kazakh cultural traditions, particularly, the dominant practices in medieval Islamic era;

- a component analysis of the forms, structures and organisation of the architectural styles included in the building; and

- an adoption of a logical structure of the sign system within the selected case study.

\section{The Main Theory}

The essence of human life is a pillar on which any society stands. The same applies to the cultural environment that surrounds a human being and to the universal path of civilisation in general. By examining the relics of a symbolic significance, we see that the world, life, society, culture and tradition are filled with universal spiritual values which are beyond time and space.

The characteristic nature of symbols affects people's aesthetic feelings. Therefore, we can see that symbols play an important role in social life. This unique feature of symbols is characterised in a worldview related to an image of the truth. The essence of symbols is not only connected with abstract ideas but also closely related to emotional excitement and aesthetic views. These qualities, meaning that the content-rich value of deeply internalised symbols contributes to the consolidation of thoughts, actions and aspirations of people. Sometimes symbols are used in the most important events of historical significance.

The function of the symbol is characterised by some qualities. We can define its relation to a language or culture, its semantic infinity, semiotic imagery, the complexity of its structure, and its emotional impact on us (Ivanov, 2004: 189).

We can consider human history as a continuous process of discovery of our spiritual being. Throughout its history, humankind has shown the artistic qualities, attitudes and thoughts. It created systems of understanding explaining the world and the images conveying those understandings (Borbassova et al., 2016: 122).

E. Cassirer was the first who developed a theory of symbolism and expanded phenomenology of knowledge into a more general philosophy of culture. The concept of the culture, he founded was semiotic. According to E. Cassirer (2002: 270), all aspects of human life have a symbolic meaning. This theory is formed on the idea that human life consists in its essence of symbols. In his Philosophy of Symbolic Forms, he considers mythology, religion, and science as a cultural and symbolic system. E. Cassirer (2002: 397) noted that everyone lives in his symbolic world. In other words, symbolism is culturological. It makes sense to an individual as it puts everything in order.

The heritage of any nation remains embedded in its material and spiritual culture. Thus, a symbolic language is a vehicle to convey national consciousness, including objective and subjective factors of cultural and social behaviour (Cassirer, 1998: 794).

According to C. Levi-Strauss (2001: 512), within the socio-cultural world, first of all is the world 
of symbols. Y.M. Lotman (1996) was one of the founders of cultural semiotics who defined the system of signs in culture as "semiosphere" and described its global value. For him, the main social role of culture is collective storage experience preserving and continuing collective intelligence. The sign represents the essence of life, behaviour and characteristic features of the world around us. The sign is a symbol, a material phenomenon, a vivid image that portrays an abstract idea or concept its form (Borbassova and Zmumagulova, 2014: 218). The classification of signs is of particular interest to our study, so in this regard, one cannot deny that any visible symbols are outside the encoded language. On the other hand, index and icon issues seem to be somewhat controversial (Peirce, 1999: 199-217). For example, Peirce identified the icon as a sign with a specific natural identical object. We can guess in what sense he understands the "natural analogy" between portrait and man, and, as for the diagrams, Peirce considers them to be iconic signs, since they convey the form of existing relationships (Peirce, 2000: 421).

Morris (1993) further developed this idea because it seemed to him as a convenient approach to a semantic determination of the image. For Morris, the icon is a sign with a marked object with some properties in it, or a "sign which possesses properties of its denotation."

Since the symbolic world of the Korkyt Ata Complex is the object of the study here, first of all, we give a theoretical explanation of the symbols in symbolic dimensions. Seisen Mukhtaruly (insert year), a scholar and a researcher of Korkyt Ata, thought that it would be necessary to approve two names for two independent constructions to distinguish between the new Korkyt Ata Complex and the ancient Mausoleum of Korkyt in the old cemetery. The names assigned to these two cemeteries of Korkyt are fixed in the reference books. The ancient building should be named the Mausoleum of Korkyt as it was before, but a new construction should be called the "Korkyt Ata Kesheni" (Eng. Korkyt Ata Complex") without any mention of international terms, such as
"Complex", "memorial", or "obelisk". This idea came true, and nowadays the Complex is called the "Korkyt Ata Kesheni".

The Mausoleum of Korkyt Ata is a historical and architectural monument. It was built approximately in the $9^{\text {th }}-10^{\text {th }}$ centuries in Karmakshy district of the Kyzylorda region, $3 \mathrm{~km}$ from the Korkyt station. It has begun to collapse since the 1950s before being washed away by the Syrdarya river in 1952. Its remains have not been located since. The Mausoleum was studied by A. Divayev, I.A. Castanet and P.I. Lerh at the end of the $19^{\text {th }}$ century. The existence of the Mausoleum became known because of the photos published in the Turkestan album collection.

According to A.Divayev and I.A. Castanet, it was a round, 6-8-sided, dome-shaped structure built of raw brick. It was tall from the inside; the walls are engraved with the ornament of "kerege" (Eng. wall part of the yurt made of thin birch). Its construction followed the model of Pre-Islamic Turkic architecture. A modern memorial monument was erected on of the Mausoleum (Nysanbayev, 2004: 58). The Complex has become a sacred place of worship for the people from the Turkic-speaking countries. The architecture is of particular importance for the overall significance of the Complex. The Korkyt Ata Complex is located on the top of a natural hill close to the Korkyt station, $18 \mathrm{~km}$ North-West from the village of Zhosaly, in Karmakshy district of the Kyzylorda region. The Monument of Korkyt Ata is a unique example of architectural art. The construction of the Complex was started in 1980; an architect B.A. Ibrayev and a physicistacoustician S.I. Issatayev had made the design.

The Complex attracts considerable numbers of people due to its spiritual significance and is believed to have a positive impact on the visitors. Architects effectively used the natural advantage of the high hill located in between the railway and highway and utilised the space from the foot to the top of the hill.

Restoration of the monument was made in 1997. A whole architectural ensemble includes an amphitheatre, a prayer house, that is, room under the mausoleum and a ram-shaped 
sculpture. All these became a memorial Complex. A museum and an administrative building were opened near the Complex in 2000. Since then, it has been a branch of the regional museum. The local authorities provided the funds from the regional budget in 2014 to renovate the Korkyt Ata Complex, namely its most important objects such as the museum, the underground prayer house, the amphitheatre, the stele and the sculpture of the ram, using durable construction materials. The Complex has high artistic, historical and mythological significance.

\section{Results}

Korkyt is primarily a father of kuy for Kazakhs (Eng.kuy - instrumental music performed by soloists using Kazakh traditional musical instruments, e.g. dombra, kobyz). He was the first who performed kuy playing the kobyz (Eng. kobyz is an ancient Kazakh string instrument). The Kazakhs are the only nation among the Turkic people who have been able to preserve the kuys of Korkyt, the clairvoyant shaman who predicted the fate of people playing his kobyz. Listening to the kuy or performing the kuy is a wonderful musical, aesthetic and psychological experience. Thanks to this experience, future generations were able to enrich and produce powerful and beautiful kuy, songs, poems and other types of art. Thus, music became a part of the spiritual heritage of the conscious generation.

Thus, one of the elements of the Complex is the 12.1-metre and 5.3-metre wide kobyz stele made of Korday stone. Each side of the stele looks like a gravestone facing the four cardinal directions. The tops are expanded in a ladle-ish shape; which is also a clear reference to the kobyz. There are 40 metal tubes in the central hole at the bottom of the joint. When the wind blows, they produce a kobyz-like sound. The legends speak of a kobyz on the Korkyt Ata mausoleum that "sings" together with the wind. The main interpretative mystery of the kobyz set up on the Korkyt Ata Kesheni refers to being in a special state of mind. Feeling the mystery of life and even the mystery of being through the sounds a kobyz makes means feeling the mystery of Korkyt's kuys. When vision and listening are connected like this, one can deeply perceive the meaning of the music composition. When the steppe wind blows, visitors may hear the kuy of the kobyz. One may feel the Great Steppe while listening and looking at the spectacular views around. Moreover, when listening, one connects musical phrases with visual images. This is a particular impact kuy makes on the listeners.

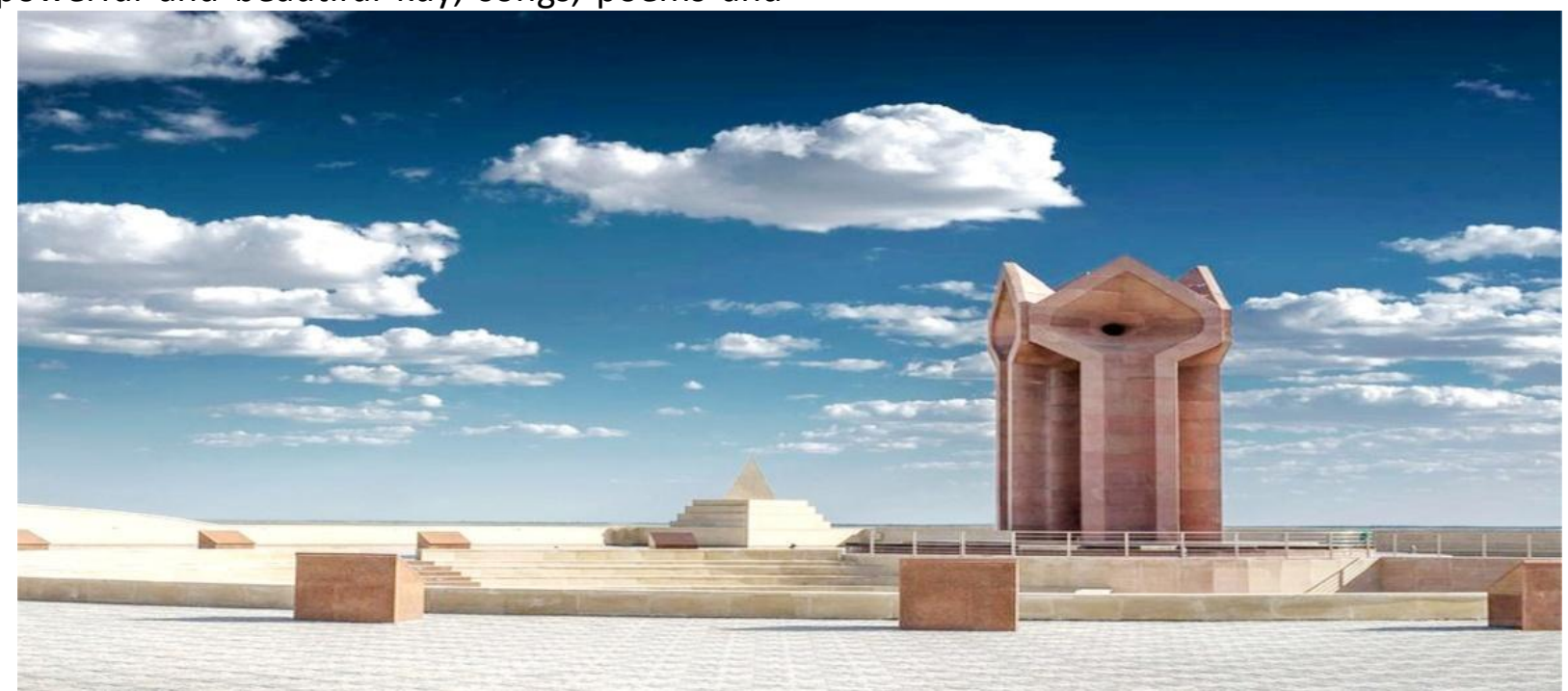

Figure1: Korkyt Ata Complex Source: Photo courtesy of the author 
The inside of the Korkyt Ata monument is decorated with "Tuye Taban" ornament (Eng. Camel's Trail) which depicts the trail of the sacred Zhelmaya (Eng. the camel which is as fast as the wind) that belonged to Korkyt Ata, the bard who looked for eternal life. The "Tuye Taban" ornament became the symbol of a long journey. Thus, from the symbolic point of view we may guess at the worldview, thoughts, dreams and interests of the ancient nomadic people.

The "Tuye Taban" is a zoomorphic and complex ornament, which, as it has been said earlier, resembles a camel's trail. Sometimes it looks like "karta", "karga", "kyzylayir" ornaments. The two S-shaped lines are not joined in parallel, and the two half-oval ornaments are similar to a camel's trail. The ornament is called "Tuye Taban" as is the name of the plant with many flowers, that is also similar to a camel's trail. It also may bear the name- "tabak" (Eng. plate) ornament in some places. This is how in space and time, the human and his place in the world were conveyed symbolically by the Turkic people. The later transition from zoomorphic symbols to anthropomorphic images constitutes a turning point in consolidating the understanding of the world of the Turkic people.

The symbolic form of this ornament can be regarded as both a basic principle of ornamentation and a specific feature of the genre. It is not just a decorative component in nomadic art, generally referred to as an ornament, but an ethnic symbolic descriptivesemantic system. In this case, ornamentation is not a formal sign but rather a language of meaning. An ornament represents a fusion of spiritual and material sides of society in the form of symbolism (History of Kazakh Art, 2008: 289).

A symbol with a deep meaning is of great significance- enabling us to think about our past, to preserve main features of the history, of our ancestor's achievements in culture and art, to pass it to the next generation. From this point of view, the Complex as a platform provide a sacred spiritual experience, which transforms a person's sensations (both visual and acoustic) and emotions into a special spiritual power.
The "Tree of Eternal Life" is the next element that worth special attention. The "Tree of Eternal Life" is placed symbolically in the centre of the stele in the Complex. Ancient people believed that a golden egg appeared when Tengri created the world. The blue sky appeared from the top of the egg whereas the earth appeared from its bottom, and the first tree of life came out from the ground. Since then the Kazakhs tend to see any solitary tree to be a sacred one. We still keep tying pieces of cloth on those trees growing amidst the everlasting steppe.

The history of the Kazakh genealogy sees a population's growth as the roots of the tree. When we look deeper into the original idea, the phrase "the tree is a pillar of the world", obtains a new meaning. It may be thought to represents the cult of the Sacred Tree. The Kazakh people recognise the image of a tree made in gold and silver as a symbol of abundance.

A. Margulan (1957: 298) says that Korkyt Ata's life was a search for an internal life, he fought for it and still resisted it. Korkyt's heritage is the most vivid image that can be only be compared to the heritage of legendary characters as Prometheus or Harta. According to Kazakh legends, Korkyt spent his life fighting the fate and the creator of the world as he craved immortal life. Korkyt searched for a perfect life without death and suffering. In this sense, the "Tree Eternal Life" as a symbolic feature in the Complex is associated with the philosophy of Korkyt Ata.

However, those pieces of cloth tied to the trees by present pilgrims shall not mean tree worship. This is a mere remnant of the past. A piece of white cloth is not something without meaning. It is bound to the tree, which is considered to be sacred, or to the tree growing in the sacred, as the tree is believed to be able to save a person amidst uninhabited steppe. Similarly, people come to the Complex and tie pieces of cloth to its "Tree Eternal Life" sometimes with the coins wrapped into them.

The next symbolic content discussed in this article is closely related to the sheep breading. 
Life and livelihood of the Kazakhs has been historically dependent on it so this is one of the oldest Kazakh traditions. The Kazakh proverb Mal osirsen koi ousir, onimi onin kol-kosir (Eng. One shall raise sheep to have an abundance) has a deeper meaning. Sheep is also a sacred animal. Its tutelary saint is "Shopan Ata" (sometimes called "Koshkar Ata"). When asking Shopan Ata for the grace, one should say "Maldi bersen, koidi ber" (Eng. If you give cattle, give the sheep).

Similar to the foundation of the philosophy of other nations, the Kazakh philosophy also begins with myths, legends and fairy tales. The ancient Turks worshipped the spirits of their ancestors. People made sacrifices; a lamb, often the firstborn in the flock.

The Kazakh people believed strongly in holy spirits; people would call upon spirits during the times of greater difficulties and hardship, they would make sacrifices and would believe that their luck was the grace of the holy spirits. Whenever one thinks about his ancestors, he says, "The spirits support me". He would go to a shrine, spend the night there and make a wish while slaughtering the cattle. For instance, the "Shora Batyr" poem, depicts the mother telling Shora's father: "Let us get one-humped camel out of the camel, a stallion out of the horse, a bull out of the cow, a ram out of the sheep and let us go to wish a child".

Our ancestors not only knew the secrets of sheep breeding, but they also entrusted later generations with many words related to the names of their young stock. The word "Koshkar tumsik" is one of them. It also has a symbolic significance literary meaning "hawk-nosed", "curved nose". That is to say; it is similar to the nose of a ram which is also curved. Thus, Zh. Aimauytov's novel contains the following description: "I am a swarthy-faced, of average height, hawk-nosed, mustached, hollow-eyed man". We can also read the following lines in the writings of I. Esenberlin (2005): "Tall, pale man with curved nose and brown eyes was not lost even though too many eyes gazed on him". It should be noted that the word "koshkar tumsik" (Eng. hawk-nosed, curved nosed) is one of the epithets widely used to describe facial features of literary characters.

The significance of sheep symbolism is also reflected in the Korkyt Ata Complex. Thus, a sculpture of Koshkar (Eng. ram) is placed in a circular court with a diameter of 36.4 metres. The sculpture length is $165.5 \mathrm{~cm}$; its width is 85 $\mathrm{cm}$ and its height is $120 \mathrm{~cm}$. The sculpture made of Korday granite is placed on a 220-centimetre high five-level pedestal. Koshkar is a prey of Kok Tengri and a symbol of the protection against the evil forces popular in the ancient Aryan and Kazakh mythology. Therefore, the sculpture in the Complex is the image of a ram and the Saka griffin with its griffin's head, wings and legs making it similar to that of a sphinx.

Another structural part of the Complex is the "Kiluet" (Eng. underground prayer house) or "Tower of Wishes". According to scholarly opinion, "Kiluet" is the Arabic word meaning "solitude", "being cut off the world", "hermitage", spiritual self-perfecting as a way to worship the Lord with Khoja Ahmed Yasawi being a pioneer of such practices among the Kazakhs.

This ancient symbolism is kept in the Korkyt Ata Complex, and the "Kiluet" was built, an underground prayer house where one can make a wish alone away from the hustle and bustle of everyday life, with clear mind, in harmony with nature, worshiping the Creator. All this is meant to have a huge spiritual impact on people. There are small holes in the walls for wick lamps. One should go downstairs to get to the prayer room.

The "Tower of Wishes" symbolism may have different meanings to different people. Pilgrims go round the tower three or seven times, then take off the shoes, decent into the tower chamber and ask for the fulfillment of their cause. Newlyweds visit the Korkyt Ata Complex, they pray, tie pieces of cloth to the Tree and receive the blessing of the elderly. They should go three times clockwise round the "Tower of Wishes", enter a small chamber and wish for whatever they want.

The intention is generally related to the objective a person has and specifies his/her 
course of action. Therefore, intentions of citizens, who come to the Complex, can be considered as enthusiasm. If we consider intention as a concept, its essence deriving from various circumstances is a reflection of a deed and aspiration. Similarly, aspiration is a form of intention.

If intention is a matter of substance, deed and aspiration are forms of intention. A deed itself has nothing to do with labour; in fact, it is associated with action.

There are other forms of intention frequently used in our national identity, such as wish and a blessing. Wish is not an intention. A wish is a characteristic feature of intention. A wish does not have a material value. Therefore, to express one's intention is to express a wish, but blessing has become a ritual service.

To come to visit the Complex and express the intentions and receive the blessing from Korkyt Ata has become a tradition the local people. What is the meaning of such a tradition? The meaning is in expressing an intention. A good wish is a thing peculiar to intention, while blessing has sacrality in it. Thus, we can state that blessing is the symbolic mark of a pure intention.

If we further analyse the Korkyt Ata Complex from a semiotic perspective, we can notice that visually and structurally the Complex has a symbolic meaning too. For example, the amphitheatre was built in a classical Roman style with a round court in the centre and spectators' sitting areas around ascending gradually to the central performance area. The amphitheatre covers 536 sq. metres; its the bottom diameter is 6 metres and the upper diameter is of 25 metres. The amphitheatre is capable of occupying 2000 people.

At the same time, if one looks closer at the amphitheatre, one realises that the Complex represents the lower part of the kobyz and amphitheatre represents the body of the kobyz. The "Korkyt and Music of the Great Steppe" festival is held there traditionally once every two years where the people gather from all the Turkic-speaking countries.

The fact that the festival was conceived as an open-air event is also meaningful because of the blue sky symbolism. The blue sky, bright sun and clear moon from Tengrian perspective are the most sacred powers. The Tengri worshipers recognised the Heaven and the Sun as the powers to create the world, and the Heaven would endow the Kagan (Eng. title of Emperor of Turks) with its might. This is what the OrkhonYenisey monument scripts tall us: "There is the blue sky above and the earth below when human children are born in the midst of them". Those words were written about Bilge Kagan in the Kultegin monument scripts: "My God has been gracious to me, protected me, I was lucky and became the Kagan". The blue colour and purity of the sky is a symbol of youth and spring, abundance, independence and freedom. It is no coincidence that the colour of the flag of Independent Kazakhstan is also blue. It is a continuation of the tradition that has been preserved by numerous nations from all over the world for thousands of years.

The next object of our semiotic analysis is the building of the museum, which is a one-story structure resembling the letter " $G$ ". The dimensions are $15.9 \times 14$ metres. The building consists of 3 exposition halls containing historic and cultural artifacts dating in the Korkyt Ata times. The museum contains around 700 exhibits. The valuable artifacts convey deep symbolic meanings of our traditions, the mysterious world reflecting our mentality and help to establish a deeper connection between the past and the present, encouraging a love for and appreciation of our national culture.

The high platform with the stele, the underground prayer house, and the amphitheatre are made of granite and surrounded by a high concrete 3.9-metre high wall around the court covering $74.22 \times 67.18 \mathrm{sq}$. metres. 


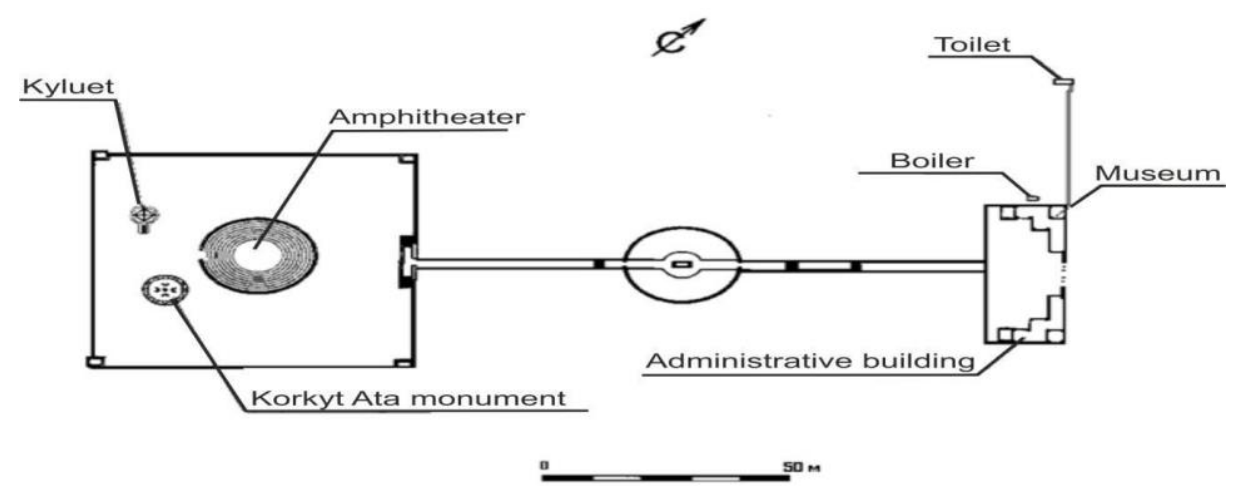

Figure 2: Korkyt Ata Complex Scheme

Source: Scheme courtesy of the author

\section{Discussion}

The people who come to visit the Complex are supposedly able and willing to decode its cultural symbolism. It is also important to note that the Complex, as an architectural ensemble, contains the symbols of many epochs and forms its universal meaning that shall withstand time.

The two-dimensional nature of the experience is worth special attention while interpreting nonverbal signs presented to us; these are those of the Complex and those of the people coming to the Complex. These two dimensions are discussed in "Semiotics of the Scene" by Y.M. Lotman (1996). He argues that the meaning of the event may differ for the people on stage because it is an occurring event being physically experienced by them, whereas for the spectators in the audience, it is a sign representing something. Furthermore, this Complex is also considered as a great stage, an important event of spiritual value for the Complex visitors.

In pragmatic terms, the life experience of Korkyt, the historical figure is like an advanced spiritual example of living that was given to humankind by the High Spirit. That is, the Complex, with its symbolic content, is reckoned to demonstrate the way to the visitors who visit for pilgrimage; to help to comprehend the ancient Turkic wisdom of great philosophical and spiritual significance.

If we read the symbolic language of the legends, Zheruik is to be understood where Korkyt Ata achieved his happiness, and his native palce is the Land of Syr; the kobyz is an instrument of escaping in Korkyt Ata and "Bak tayagi Kok tiregen aulie kart" (Eng. One old holy with white stick) mysterious forces preaching in his dreams. This kobyz was made of a bone, skin, iron, horn, horsetail hair and wood. According to some legends, it was made in the form of a swan and from a cannon bone of male one-humped camel. The character standing on the bank of the darya (Eng. big river) is a symbolic representation of spiritual growth. Water is a symbol of the truth. That kobyz of Korkyt should be taken to the "Centre of the World" and be an instrument to establish the relationship with Tengri, the God of Time, who ensures the flight of Korkyt in the space of ecstasy and melody (Korkyt Ata, 1999: 512).

To acquaint oneself with Korkyt, one has to look at his heritage from his spiritual standpoint. The heritage of Korkyt is cloaked with legends. The legend is a box of ideas that convey the allegory of truth.

The belief in the forces of nature can also be found in legends and stories about Korkyt Ata as Korkyt himself worshipped the mountains, forests and water. At the same time, the eternity of the human soul and specific cosmocentrism is central for the philosophy of Korkyt. Thus, it is about to make human life eternal, which is a very philosophical concept per se.

The Korkyt Ata Complex with its unique architecture attracts from afar. It is like a symbolic door of the spiritual world, and Korkyt Ata monument with its sounds of kobyz reminds how to appreciate every moment of life. 
According to Korkyt, eternal life is about respect - the uniqueness of each moment of time and to leave an indelible heritage through art and spirituality to the future generations. The monument atmosphere creates a particular mood energising the people who have come to visit.

Those, who come to the Complex, will be not only amazed by a scope of logical thinking but also will have the right to imbibe spiritual values. When this happens, any individual can form one's own principle of a symbolic and spiritual model. The problematic issue here is that people may not grasp the symbolism of the Complex and see it as a symbiosis of its particular elements in their integrity.

In order to avoid a superficial reception of the Complex symbolism, it is might be necessary to create a mental unity that would connect all the symbols. That is, would be necessary for the people coming to the Complex to employ their abilities of critical artistic and symbolic thinking to perceive each sign as a new form integrated within the Complex. Analytical and symbolic thinking, mythological, religious and artistic knowledge would help to understand how the interior of the Complex represents the inner world - the meaning and the form in a symbolic integrity.

However, there are some other aspects as well. If we address the Korkyt Ata Complex comprehensively, then we will view it as a symbolic and spiritual integrity. Despite the broadness of the range of symbols, they eventually bring the viewer to some kind of integrity. The Complex does not need to exist on a standalone basis because the mutual relationship between the Complex and the viewers ensures the formation of logical and causal "system".

The significance behind the Complex becomes evident when the goal of the mutual relationship is integrated into real practice. Any symbol that is present in the Complex holds a message that encourages a viewer to renew his/her consciousness and hides some creative forces in representation. Those, who come to the Complex, do not only recognise the meaning of signs as they understand them but also feel a true power of the spirit enclosed in those signs. This gives them a sense of meaning. However, this feeling is unique, it is linked to the art, myth, religion and worldview that are specific to one individual. People live in the world of images and symbols and see those images and symbols differently. They create their own symbols from one spiritual base. Newly formed symbols are independent but not divorced from each other. Because each symbol is a specific way to percept reality, every individual tries to recognise a distinctive aspect of truth. If we read the signs from the Complex in a single order, combining together the aspects of art, character, myth and cognition, then cultural values will stand out in a new light. In general, a period of the Turkic Khanate was the time of formation and spread of Turkic civilisation, of the emergence of the idea of the whole Turkic nation. From historic perspective, Korkyt may be regarded as a cultural symbol of those Turkic tribes, who had not yet fully embraced Islam. The main philosophical meaning of the Korkyt zhyr is to learn about the world and the laws of nature from artistic viewpoint (Shakirova, 2009: 346).

In this regard, every person, who is interested in his or her history, can satisfy his/her spiritual hunger by coming to the Korkyt Ata Complex and viewing the symbols.

The Complex also plays a crucial role in tourism development and in the formation of a new tradition of respect for cultural values. In general, this Complex stands there to deliver an original history and culture, to convert art into symbolic elements, to raise the feeling of national identity, and to answer questions through united signs and symbols (Aljanova, 2015:35).

In general, the Korkyt Ata Complex with its deep existential content is ding put in the universe to deliver delicately via the symbolic signs - the essence behind contemplations of the human soul.

Therefore, the Korkyt Ata Complex is a cultural heritage of a modern person, who lives in a progressive information society. The person, who comes to the walls of the Korkyt Ata 
Complex, understands and feels the main idea of the legend about Korkyt, which is about the power of music and creativity. Impressed by it, he/she enriches his/her worldview.

\section{Conclusion}

The Korkyt Ata Complex is a representation of a deep existential content forever kept in human memory which it delivers delicately through its symbols and signs conveying the contemplations that the human soul lives in harmony within a cultural environment. Therefore, the Complex might be seen as the cultural property of a modern person. A person who comes to the Complex with the image of kobyz in his or her mind would understand the main idea of the Korkyt legend which is about the power of music and human creativity as a vehicle towards eternity.

Korkyt Ata is the major symbol of honour and spiritual truth. Symbols that are used in the Korkyt Ata Complex together form a historical, spiritual and informative social space. The Complex encourages cultural tourism to the Land of Syr and realises its spiritual potential.

At the same time, the Korkyt Ata Complex as a modern monument of preserving the ancient Turkic heritage is the storage of invaluable spiritual systems codified symbolically to maintain the effective transfer of cultural knowledge within the cultural continuity. The Complex symbolises the search for harmony between human and steppe. The semiotic analysis of its symbols is important in this context. The Korkyt Ata Complex represents a modern view on the cultural heritage of the ancient Turkic people and, due to its encouragement of cultural tourism, is already considered as a civilisational factor making the positive impact on independent Kazakhstan.

\section{References}

Aljanova, N., K. Borbassova and Sh. Rysbekova (2015). A Semiotic Analysis of the Yurt, Clothing and Food Eating Habits in Kazakh Traditional Cultures, The International
Journal of Critical Cultural Studies, 14(1), pp. 35

Borbassova, K. M., and S. Zhumagulova (2014). Foundation Semiotic Science. Paper presented at the Republican Scientific Practical Conference, Almaty, Kazakhstan, pp. 218.

Borbassova, K. M., N. K. Aljanova and E. Karabalina (2016) Communication semiotics of the Kazakh language the manifestation of his literature, Vestnik KazNU Almaty, Journal of Philosophy, Culture and Political Science, 56, pp. 114-122.

Cassirer, E. (2002). The Philosophy of Symbolic Forms. Vol I: Language. Translation by $A$. Romashko. M.-SPb: University Book (ISBN: 594483-002-6).

Cassirer, E, (2002). The Philosophy of Symbolic Forms. Vol II: Mythical Thought. Translation by A. Romashko. M.-SPb: University Book (ISBN: 5-94483-003-4).

Cassirer, E.(1998). Shortlist. Essay on Man. M: Gardarica (ISBN: 5-7975-0039-6).

History of Kazakh Art (2008). Volume 3. 1st book. Almaty: Oner (ISBN: 9965-9249-9-6).

Ivanov, V. (2004). Selected Works on Semiotics and Cultural History. M: Nauka (ISBN:594457-117-9).

Korkyt Ata (1999). Encyclopedic Collection. Almaty: Aruna (ISBN 5-89800-129-8)

Levy-Strauss, C. (2001). Structural anthropolog. M: Exmo-Press (ISBN: 5-04-008349-1).

Margulan, A. (1957). The legend of Korkyt, Kazakh fairy tales. Almaty: Zhazushy.

National Encyclopedia of Kazakhstan (2004). Volume 6. Almaty: Kazakh Encyclopedia (ISBN 9965-9389-7-6

Peirce, Ch. S. (1999). Logic as semiotics: the theory of signs. Metaphysical Research. Language. SPb (ISBN 5-89329-146-8).

Peirce, Ch. S. (2000). Selected philosophical works. M: Logos (ISBN: 5-8163-0014-8). 
Shakirova, M. I. (2009). Korkyt and kobyz music. Paper presented at the International Conference Aral-Syrdariya region in the history and culture of Eurasia, Kyzylorda, Kazakhstan. Pp. 344-349 